\title{
Role of Humic Acid Chemical Structure Derived from Different Biomass Feedstocks on Fe(III) Bioreduction Activity: Implication for Sustainable Use of Bioresources
}

\author{
Yuquan Wei ${ }^{1}$, Zimin $\mathrm{Wei}^{2}$, Fang Zhang ${ }^{1}{ }^{(}$, Xiang $\mathrm{Li}^{3}$, Wenbing Tan $^{3}$ and Beidou $\mathrm{Xi}^{1,3, *}$ \\ 1 School of Environment, Tsinghua University, Beijing 100084, China; weiyq2013@gmail.com (Y.W.); \\ fangzhang@tsinghua.edu.cn (F.Z.) \\ 2 College of Life Science, Northeast Agricultural University, Harbin 150030, China; weizm691120@163.com \\ 3 State Key Laboratory of Environmental Criteria and Risk Assessment, Chinese Research Academy of \\ Environmental Sciences, Beijing 100012, China; david2013marshall@outlook.com (X.L.); \\ wenbingtan@126.com (W.T.) \\ * Correspondence: wbtann@126.com; Tel.: +86-10-8491-3133
}

Received: 24 April 2019; Accepted: 14 May 2019; Published: 15 May 2019

\begin{abstract}
Humic acids (HAs) are redox-active components that play a crucial role in catalyzing relevant redox reactions in various ecosystems. However, it is unclear what role the different compost-derived Has play in the dissimilatory Fe(III) bioreduction and which chemical structures could accelerate Fe reduction. In this study, we compared the effect of eighteen HAs from the mesophilic phase, thermophilic phase and mature phase of protein-, lignocellulose- and lignin-rich composting on catalyzing the bioreduction of $\mathrm{Fe}(\mathrm{III})$-citrate by Shewanella oneidensis MR-1 in temporarily anoxic laboratory systems. The chemical composition and structure of different compost-derived HAs were analyzed by UV-Vis spectroscopy, excitation-emission matrices of the fluorescence spectra, and ${ }^{13} \mathrm{C}-\mathrm{NMR}$. The results showed that HAs from lignocellulose- and lignin-rich composting, especially in the thermophilic phase, promoted the bioreduction of Fe(III). They also showed that HA from protein-rich materials suppressed significantly the Fe(II) production, which was mainly affected by the amount and structures of functional groups (e.g., quinone groups) and humification degree of the HAs. This study can aid in searching sustainable HA-rich composts for wide-ranging applications to catalyze redox-mediated reactions of pollutants in soils.
\end{abstract}

Keywords: Humic acid; Bioreduction of dissimilatory Fe(III); Shewanella oneidensis MR-1; Redox-active structures; Composts from different sources

\section{Introduction}

Humic acid (HA) is one of the most important components of humic substances as it plays a crucial role in regulating carbon cycles and catalyzing relevant redox reactions in various ecosystems $[1,2]$. Under anoxic conditions, both dissolved and particulate HA may accept electrons from anaerobic microbial respiration. Reduced HA can also serve as an electron donor and transfer electrons to poorly soluble $\mathrm{Fe}(\mathrm{III})$, mediating dissimilatory $\mathrm{Fe}(\mathrm{III})$ reduction and affecting their transformation and speciation [3]. It is widely accepted that quinone moieties, as well as other redox-active functional groups in the HA, have an important role in electron shuttling process, thereby affecting microbial electron transfer onto Fe(III) [4]. Therefore, this process has received a great deal of attention owing to the broad impact of dissimilatory iron reduction on the geochemical cycles.

Composting is a controlled biological transformation process to stabilize different organic solid wastes, which is generally divided into mesophilic phase, thermophilic phase, and mature phase [5]. 
Numerous studies have found that microbial degradation reduced the soluble organic carbon content and promoted the formation of HA with increasing molecular weight and aromatic characteristics during composting [6]. Composts from different sources may form diverse humic substance precursors (e.g., polyphenols, carboxyl acids, amino acids, reducing sugars, etc.) due to their different organic compositions, causing HA produced by composting to have different molecular composition and chemical structures [2,7]. The HA with the functional groups including phenolic, alcoholic, quinone, ketone, nitrogen and sulfur redox-active moieties as well as organic-metal chelates could mediate electron transfer process and enhance the reduction rate of ferric oxy/hydroxides [8]. Considering different microbial activities at varied composting periods, HA from different stages of composting may also have different composition and functional groups. A study has shown that HA precursors are mainly formed in the mesophilic or thermophilic phase and HAs are polymerized in the mature phase [9]. Therefore, compost-derived HA from different sources and different stages may have diverse redox-active potential for accelerating microbial electrons transfer. Fe(III) is an important terminal electron shuttle and its redox transformation is crucial to stimulate the biodegradation of organic contaminants. Although various papers from the literature have already studied on the relationship between the dissimilatory Fe(III) bioreduction and HA [3,4], few research papers have explored the roles of different compost-derived HA as redox mediators in dissimilatory Fe(III) bioreduction and which chemical structures could accelerate Fe reduction.

In this work, we isolated eighteen HAs from mesophilic phase, thermophilic phase and mature phase of protein-, lignocellulose- and lignin-rich composting to determine their effect as electron shuttles for catalyzing the microbial reduction of Fe(III)-citrate by Shewanella oneidensis MR-1 in temporarily anoxic laboratory systems. We applied UV-Vis spectroscopy, 3D excitation-emission matrices of the fluorescence spectra, and ${ }^{13} \mathrm{C}-\mathrm{NMR}$ to compare the changes of chemical composition and structure of different compost-derived HA. This study aims to (1) compare the chemical structures of HA from different composting, (2) evaluate their redox capacity of mediating $\mathrm{Fe}(\mathrm{III})$-citrate bioreduction by Shewanella oneidensis MR-1, and (3) explore which chemical structure properties of HA are most responsible for accelerating $\mathrm{Fe}(\mathrm{III})$ reduction. The results of the present study can promote the application of HA-rich composts in contaminated soils.

\section{Results and Discussion}

\subsection{Bioreduction of Dissimilatory Fe(III) Mediated by Different HAs}

Composting HAs from different sources all had relatively high molecular weight and aromatic characteristics, but the ability of HAs to mediate electron transfer process and affect the reduction rate of dissimilatory Fe(III) were different. The changes of Fe(II) in different treatments during the reduction process were shown in Figure 1, which were fitted to the first order pharmacokinetic model. Shewanella oneidensis MR-1 is a typical dissimilatory iron reducing bacteria with the capable of respiring anaerobically on $\mathrm{Fe}(\mathrm{III})$ as the sole terminal electron acceptor [10]. The increase in the $\mathrm{Fe}(\mathrm{II})$ concentration after the inoculation of Shewanella oneidensis MR-1 suggested that $\mathrm{Fe}(\mathrm{III})$-citrate was bioreduced and total $\mathrm{Fe}$ (II) concentration increased steadily to around $2.254 \pm 0.003 \mathrm{mM}$ in $190 \mathrm{~h}$ in the absence of HA. With the addition of HA, Fe(III)-citrate was also reduced and gradually leveling-off $\mathrm{Fe}(\mathrm{II})$ concentration in $288 \mathrm{~h}$, but the addition of HA from six composts had different reduction extents and $\mathrm{Fe}(\mathrm{II})$ production rate. The average level of $\mathrm{Fe}(\mathrm{II})$ formation in different composts were ranked in the order WW $>\mathrm{CW}>\mathrm{GW}>\mathrm{SW}>\mathrm{CM}>\mathrm{DM}$ (Figure 2). A post hoc test for Fe(II) concentration in all the systems showed that there was a significant difference between protein-, lignocellulose- and lignin-rich composting, suggesting that lignocellulose-rich composting might have more redox-active functional groups for transferring electrons than protein- and lignin-rich composts. 

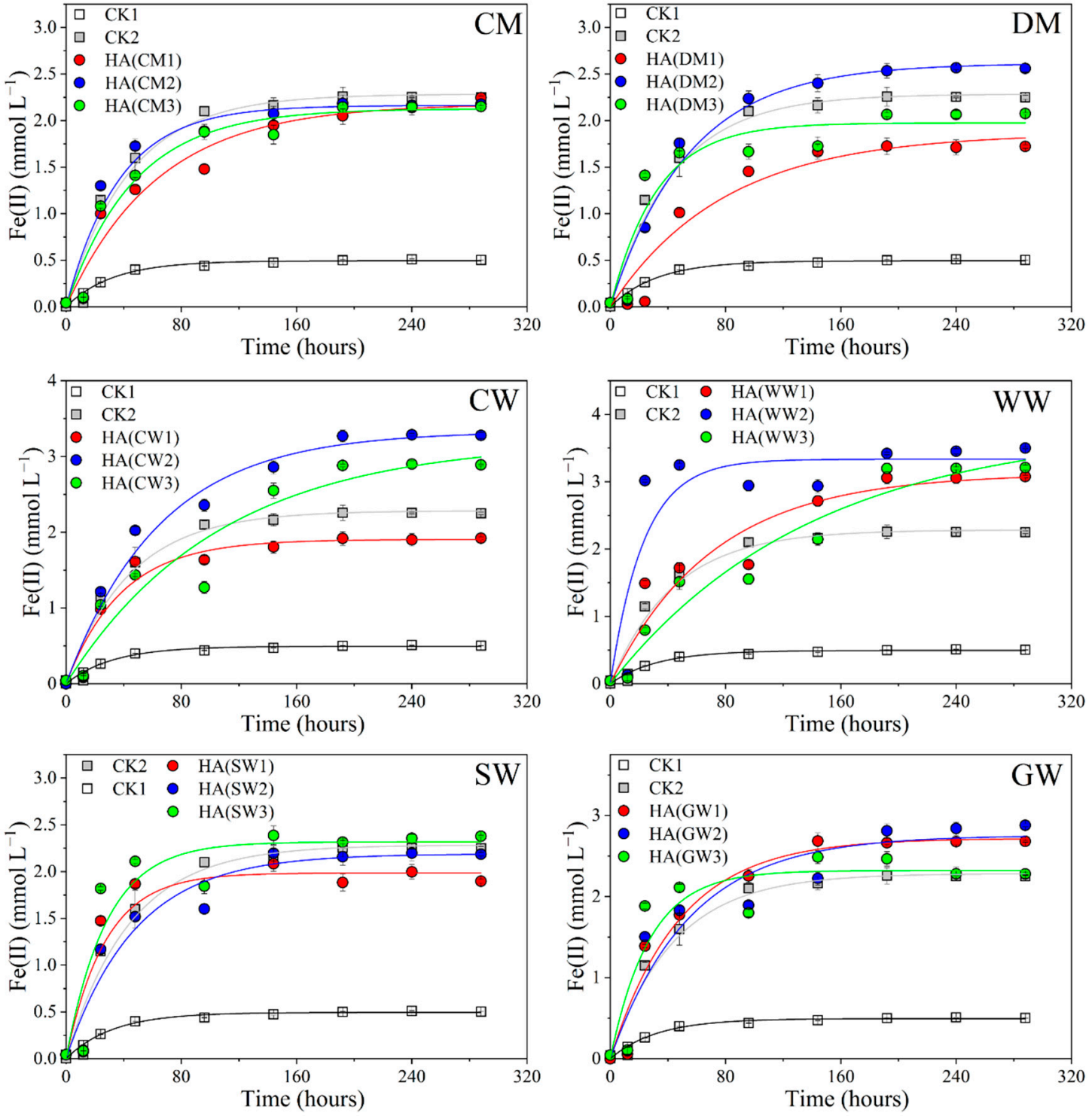

Figure 1. Effect of different compost-derived humic acid (HA) on the bioreduction of Fe(III)-citrate by Shewanella oneidensis MR-1 in cultures containing 20 mM Fe(III)-citrate, Shewanella oneidensis MR-1 cells $\left(10^{7}\right.$ cells $\left.\mathrm{mL}^{-1}\right)$, and HA (final concentration of $\left.100 \mathrm{mg} \mathrm{L}^{-1}\right)$. Lines showed nonlinear least-squares regression fits of data to an equation describing product accumulation from a first-order reaction. Bars on symbols represent standard deviations of three replicates. CK1 was blank control, CK2 was the control without HA addition and the treatments with HA addition are described in Materials and Methods.

Here, CK1 was blank control and CK2 was the control without HA addition. In the presence of HA from WW2, the reduction extents were generally 55.6\% higher than those observed in CK2, which showed the best stimulation capacity among the eighteen tested HAs. The addition of HA species from WW, CW and GW composting resulted in obvious increases of the $\mathrm{Fe}(\mathrm{II})$ production (1.2-1.5 times higher than that of control system without HA), especially in WW1-3, CW2-3 and GW2. However, when HA from CM, DM, and SW composting were added, the Fe(II) production of systems were generally lower than those obtained in CK2, especially in CM1-3, DM1, DM3 and SW1, which might have an inhibition effect on the bioreduction of dissimilatory Fe(III). In the composting of protein-rich materials, HA is easier to be formed due to more degradation of easily degradable organics but it may be unstable, which could be served as nutrient for promoting microbial growth [11,12]. For the bioreduction in DM2, more Fe(II) production by HA addition was also observed than those in DM1 
and DM3, although the stimulating effects were less significant compared to CK2, suggesting that thermophilic phase of DM composting may benefit the formation of redox functional groups of HA [13]. Though no significant difference could be found with Fe(II) production in systems with the addition of HA from different stages, the formation quantity of $\mathrm{Fe}(\mathrm{II})$ with HA obtained from the thermophilic or mature stage were generally higher than that from mesophilic stage for all the composting except $\mathrm{CM}$, demonstrating that the capacity of HA as electron shuttles was enhanced after composting $[1,14]$.
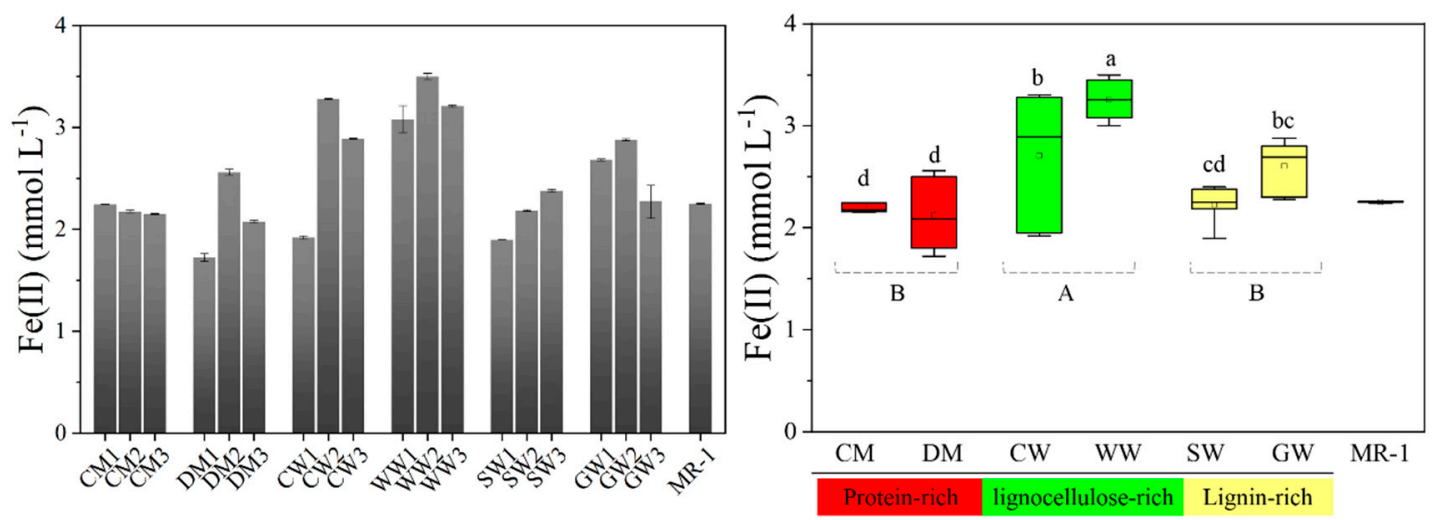

Figure 2. The Fe(II) formation of Shewanella oneidensis MR-1 with HA addition for Fe(III)-citrate bioreduction after $288 \mathrm{~h}$ in anoxic conditions with $20 \mathrm{mM}$ Fe(III)-citrate addition. Different letters (A-B, a-d) are related to significant differences. Acronyms for different treatments are described in Materials and Methods.

In this study, the bioreduction of $\mathrm{Fe}(\mathrm{III})$-citrate were fitted to first-order kinetic equation by the non-linear least-square curve fitting technique $(P<0.05)$ (Table 1$)$. Results showed that the $\mathrm{k}_{\text {red }}$ of initial $\mathrm{Fe}(\mathrm{II})$ production rates of systems with HA from thermophilic stage of lignocellulose-rich composting higher than that in CK2. The HA from mesophilic and mature stages of lignin-rich composting still demonstrated higher $\mathrm{k}_{\text {red }}$ and better stimulation capacity than only adding S. oneidensis MR-1 at initial Fe(II) production stage ( $48 \mathrm{~h}$ ), whereas the total Fe(II) production of HA from mesophilic stages of SW composting was very limited. Overall, there is an obvious stimulation capacity of HA from lignocellulose-rich composting (WW and $\mathrm{CW}$ ), and HA from protein-rich composting (CM and DM) mainly suppressed the electron transfer between the Shewanella oneidensis MR-1 and Fe(III).

Table 1. First-order kinetics equations for describing the dynamics of Fe(III) reduction.

\begin{tabular}{ccccccc}
\hline & \multicolumn{3}{c}{$\mathbf{k}_{\text {red }} \mathbf{( h}^{-\mathbf{1}} \mathbf{c}$} & \multicolumn{2}{c}{$\boldsymbol{R}$} \\
\cline { 2 - 7 } & $\mathbf{1}$ & $\mathbf{2}$ & $\mathbf{3}$ & $\mathbf{1}$ & $\mathbf{2}$ & $\mathbf{3}$ \\
\hline CM & $0.0158 \pm 0.0032$ & $0.0271 \pm 0.0060$ & $0.0213 \pm 0.0040$ & 0.9564 & 0.9384 & 0.9583 \\
DM & $0.0126 \pm 0.0037$ & $0.0183 \pm 0.0030$ & $0.0309 \pm 0.0091$ & 0.9365 & 0.9705 & 0.8917 \\
CW & $0.0260 \pm 0.0056$ & $0.0354 \pm 0.0026$ & $0.0094 \pm 0.0031$ & 0.9421 & 0.9709 & 0.9296 \\
WW & $0.0141 \pm 0.0039$ & $0.0432 \pm 0.0166$ & $0.0072 \pm 0.0022$ & 0.9263 & 0.8293 & 0.9539 \\
SW & $0.0367 \pm 0.0108$ & $0.0209 \pm 0.0048$ & $0.0356 \pm 0.0118$ & 0.8918 & 0.9378 & 0.8664 \\
GW & $0.0208 \pm 0.0041$ & $0.0182 \pm 0.0051$ & $0.0368 \pm 0.0129$ & 0.9565 & 0.9120 & 0.8517 \\
CK1 & & $0.0227 \pm 0.0044$ & & & 0.9568 & \\
CK2 & & $0.0310 \pm 0.0030$ & & & 0.9841 & \\
\hline
\end{tabular}

1,2 , and 3 represented the different stages of composting, i.e., mesophilic phase, thermophilic phase and maturation phase. Fe(III)-citrate reduction experiments were conducted in cultures containing $20 \mathrm{mM} \mathrm{Fe}(\mathrm{III})$-citrate, Shewanella oneidensis MR-1 cells $\left(10^{7}\right.$ cells $\left.\mathrm{mL}^{-1}\right)$, and HA (final concentration of $100 \mathrm{mg} \mathrm{L}^{-1}$ ) at $30^{\circ} \mathrm{C}$.

\subsection{Structural Characteristics of Different HAs}

In order to investigate the composition and chemical structures of HA from different composting, the HAs at different stages of composting were characterized firstly by the indexes of UV-Vis spectroscopy 
including $\mathrm{SUVA}_{254}, \mathrm{SUVA}_{290}, \mathrm{E}_{4} / \mathrm{E}_{6}, \mathrm{~A}_{240-440}$, and $\mathrm{S}_{\mathrm{R}}$. A number of studies have shown that $\mathrm{SUVA}_{254}$ and $\mathrm{A}_{240-440}$ were positively related to the abundance of aromatic $C$ and aromatic rings of polar functional groups of the compost-derived $\mathrm{HA}$, while $\mathrm{E}_{4} / \mathrm{E}_{6}$ and $\mathrm{S}_{\mathrm{R}}$ were negatively correlated with humification degree and molecular weight of humic substances $[15,16]$. As shown in Figure 3 , the values of $\mathrm{SUVA}_{254}$, SUVA $_{290}$ and $\mathrm{A}_{240-440}$ of HA in different composts were generally all increased from mesophilic stage to mature stage, while $E_{4} / E_{6}$ and $S_{R}$ were decreased, which suggested the increase of the polymerization of HA structure and the accumulation of the substituent group type on aromatic rings and the electron transfer band. The increase of SUVA 254 in WW, CW, GW and SW (above 20\%) were higher than those in CM and DM, indicating a higher humification degree of HA $[17,18]$. Notably, the highest values of $\mathrm{SUVA}_{290}$ was found in the thermophilic phase for lignocellulose- and lignin-rich composting, suggesting that most of the lower organic matter such as quinones and more complex compound have incorporated in the aromatic structure at the later stage of composting $[16,19]$. The changes of SUVA 290 was in agreement with the trends of Fe(II) production, thereby corroborating that the changes in quinone moieties were directly associated with redox properties of HA in composts.
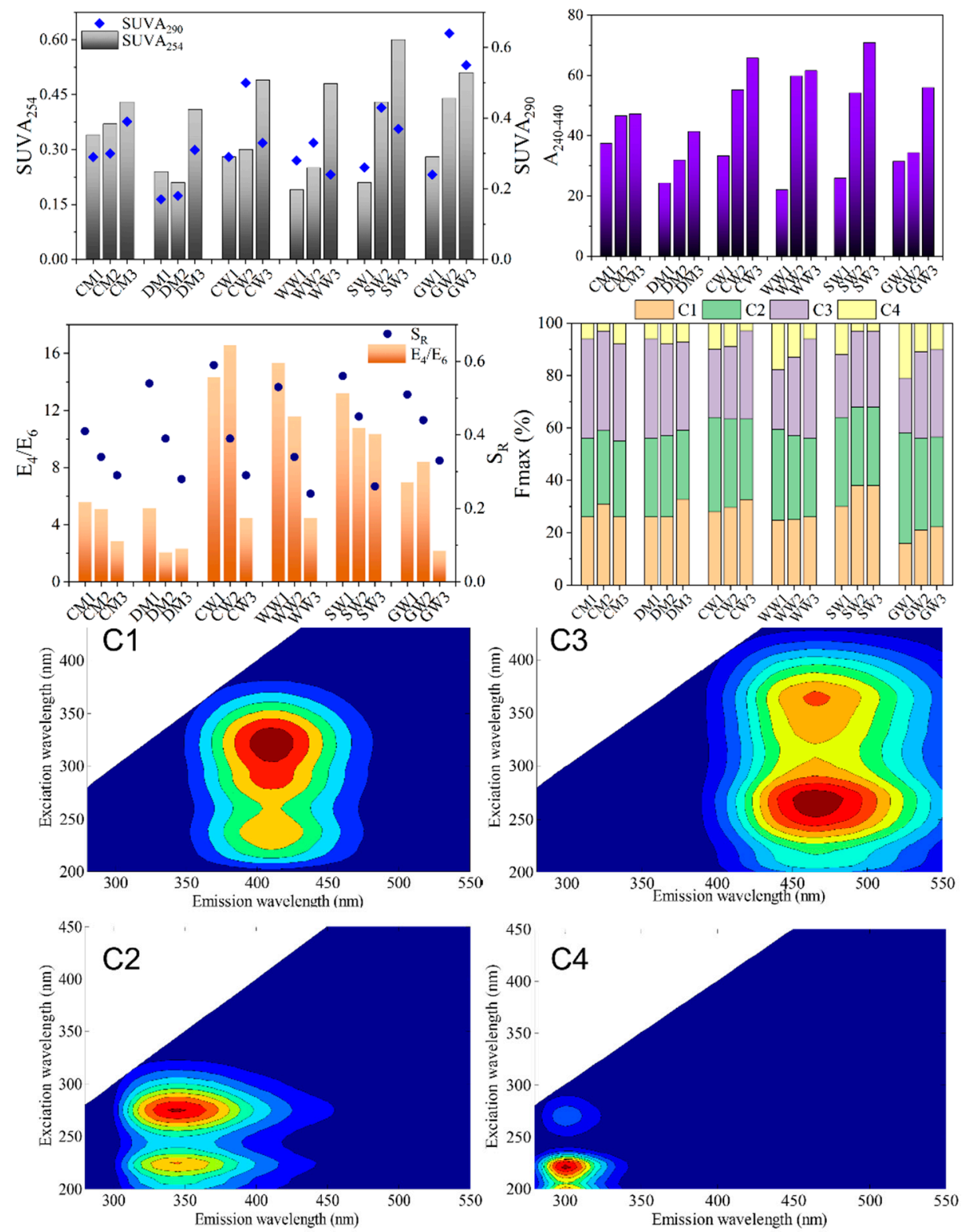

Figure 3. The analysis based on UV-Vis spectroscopy, and fluorescence spectroscopy for the chemical structures of different compost-derived HA. Acronyms definitions can be found in the Abbreviations list. 
Parallel factor (PARAFAC) analysis showed that four components were identified to explain most of the HA variation from different composting (Figure 3). Component 1 (C1) and component 3 (C3) was characterized as fulvic-like and humic-like substances, respectively. Component 2 (C2) was attributed to tyrosine-like substances and component 4 (C4) was associated with soluble microbial byproduct-like material with a few tryptophan-like substances [20]. There were obvious differences in Fmax among components of HA from different composts $(P<0.05)$, which decreased as follows: $\mathrm{C} 2$ $(32.22 \%), \mathrm{C} 3(31.72 \%)>\mathrm{C} 1(27.94 \%)>\mathrm{C} 4(8.78 \%)$. However, each fluorescence components of HA presented different content in different composts due to their different organic compositions and humic substance precursors $[6,21]$. There was no significant increase of fulvic-like and humic-like substances in $\mathrm{CM}$ and DM. An obvious increase in the combination of $\mathrm{C} 1$ and $\mathrm{C} 3$ was identified in HA from WW, CW, GW and SW. This indicated the synthesis of HA that are chemically and biologically more stable in lignin- and lignocellulose-rich composting.

In order to better understand the difference of these chemical structures of HA from diverse composting, ${ }^{13} \mathrm{C}-\mathrm{NMR}$ was monitored, which indicated the presence of many types of carbons, including aliphatic, carbohydrate, aromatic, and carboxyl carbons, with a wide variation in the relative abundance of aliphatic vs. aromatic carbons in HA. As depicted in Figure 4, the peak intensity of alkyl C region were obviously decreased from mesophilic stage to mature stage in protein-rich composting, followed by lignocellulose-rich composting. The peak intensity of aryl $\mathrm{C}$ region were increased in all the composts. In the mature phase of different composts, there was a significant increase in peak intensity at 148 and 153 ppm, which represent methoxy-/hydroxy-substituted phenyl $\mathrm{C}$ and oxygen-substituted aromatic $\mathrm{C}$, respectively [22]. ${ }^{13} \mathrm{C}-\mathrm{NMR}$ of $\mathrm{CM}, \mathrm{DM}$, and $\mathrm{CW}$ exhibited common major peaks at 50-110 ppm, suggesting abundant precursors of hydroxyl and amino acids for the formation of redox-active functional groups of HA [23]. HA from WW, SW and GW exhibited peaks between 170-185 ppm, confirming the presence of carbonyl groups from ester, carboxylic acids, quinone, ketone, etc. An increase of carbonyl groups could be found during composting of CM and DM, suggesting that lignin- and lignocellulose-rich organics were easier for arylation during composting and protein-rich organics were easier for carboxylation to form different $\mathrm{HA}$ [9]. The trends of ${ }^{13} \mathrm{C}-\mathrm{NMR}$, UV-Vis spectroscopy and EEM fluorescence plots explained the structural changes of HA during composting and obvious differences of HAs from different materials. These results suggested that HA from lignocellulose- and lignin-rich composting, especially in the thermophilic phase had more polar functional groups with redox activity such as phenolic, alcoholic, quinone and ketone groups, nitrogen and sulfur redox-active moieties, as well as organic-metal chelates.

\subsection{The Potential Role of HA in Dissimilatory Fe(III) Bioreduction}

The data in Figure 5 gives an indication of the interdependence of two random variables that range in value from -1 to +1 . SUVA 254 was positively correlated with $\mathrm{A}_{240-440}(P<0.01) .{ }^{13} \mathrm{C}-\mathrm{NMR} 3$ was positively correlated with ${ }^{13} \mathrm{C}-\mathrm{NMR} 2$ but they were both negatively related to ${ }^{13} \mathrm{C}-\mathrm{NMR} 1,{ }^{13} \mathrm{C}-\mathrm{NMR}$, $\mathrm{C} 2$ and $\mathrm{E}_{4} / \mathrm{E}_{6}$, suggesting that the formation of aryl $\mathrm{C}$ and hydroxyl $\mathrm{C}$ fractions was directly sourced from degradation of tyrosine-like substances and alkyl $\mathrm{C}$ for the condensation of $\mathrm{C}$ skeletons in different composts. Correlation analysis showed that $\mathrm{SUVA}_{290}$ was positively correlated with $\mathrm{C} 1$, but negatively with $S_{R}$. This result supported that quinones might act as main fractions of the fulvic-like substances with high molecular weight structure [24]. A strong positive correlation between ${ }^{13} \mathrm{C}-\mathrm{NMR} 4$ and $\mathrm{C} 2$, $\mathrm{C} 4$ as well as $\mathrm{E}_{4} / \mathrm{E}_{6}$ was observed, indicating that carboxyl and protein-like matter could be used by the microorganisms and obviously promote the formation of HA with a high degree of humification [25]. 


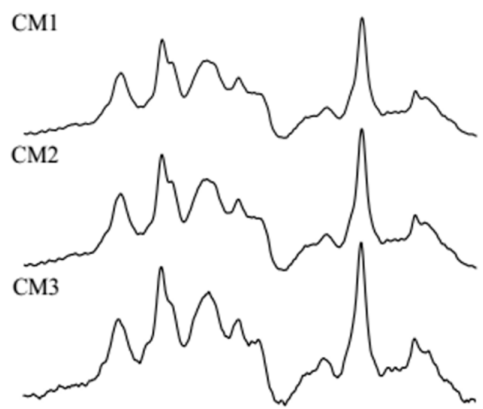

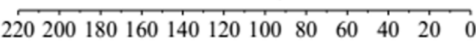
FVW1

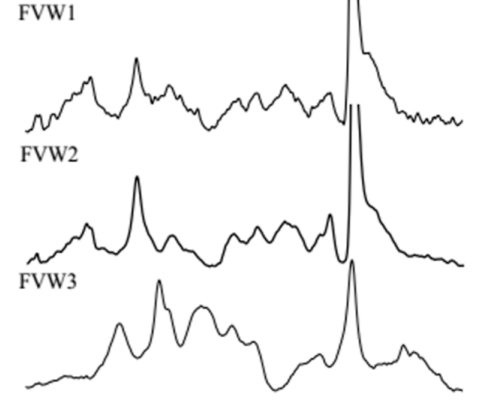

$22020018016014012010080 \quad 6040 \quad 2000$

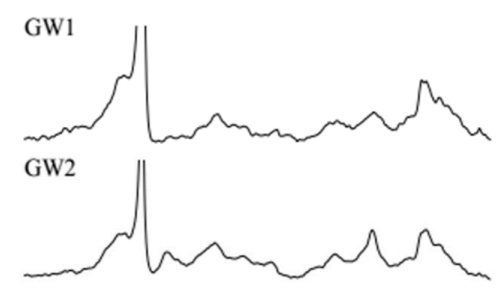

GW3

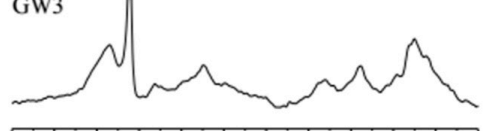

$\begin{array}{lllllllllllllll}220 & 200 & 180 & 160 & 140 & 120 & 100 & 80 & 60 & 40 & 20 & 0\end{array}$
DCM1

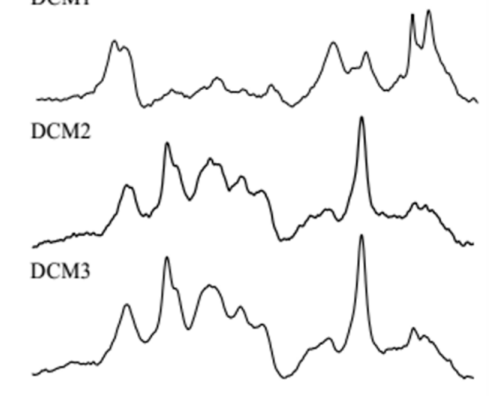

$\begin{array}{llllllllllllll}220 & 200 & 180 & 160 & 140 & 120 & 100 & 80 & 60 & 40 & 20 & 0\end{array}$

WW1
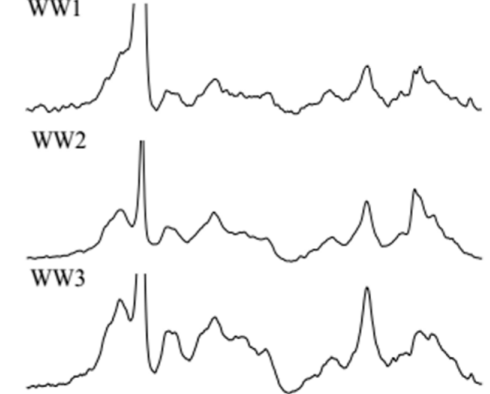

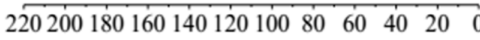

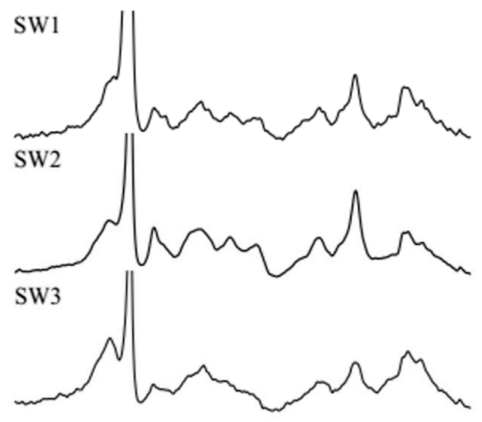

$\begin{array}{llllllllllllll}220 & 200 & 180 & 160 & 140 & 120 & 100 & 80 & 60 & 40 & 20 & 0\end{array}$

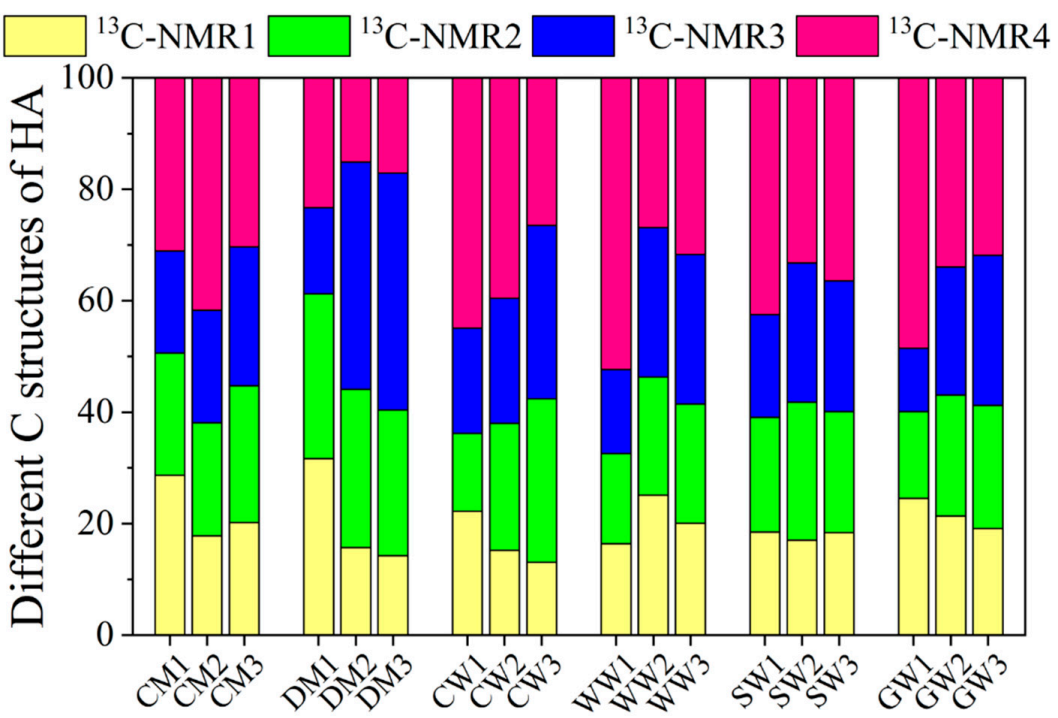

Figure 4. The solid state ${ }^{13} \mathrm{C}-\mathrm{NMR}$ spectrum of HA during composting. Acronyms definitions can be found in the Abbreviations list. 


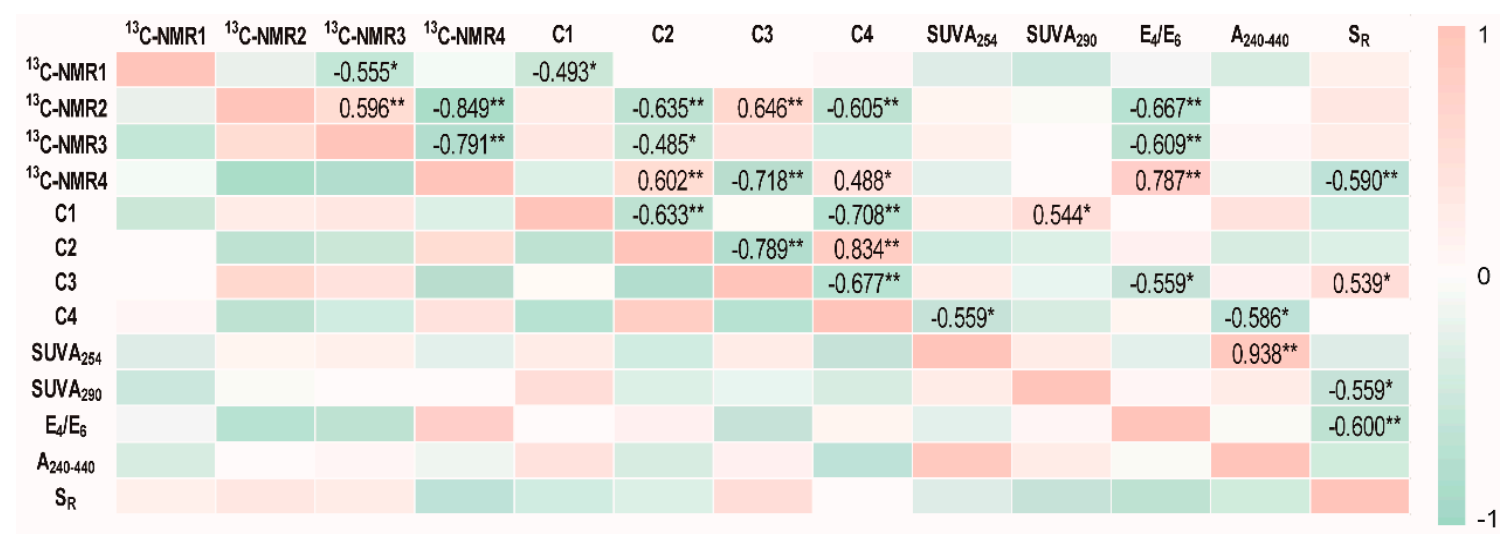

Figure 5. Pearson correlation matrix between the chemical structure parameters of HA from different composting. ${ }^{*}$ Significant at $P<0.05$. ${ }^{*}$ Significant at $P<0.01$. Colors are proportional to values in table (correlation coefficient). Acronyms definitions can be found in Materials and Methods.

In order to determine to what extent different chemical structures of HA from different composts affected the dissimilatory Fe(III) bioreduction, RDA was performed based on the spectral dataset and $\mathrm{Fe}(\mathrm{II})$ production indexes of different HA treatments. Figure 6 indicated an ordination graph where the first and all canonical axes were highly significant based on Monte Carlo tests $(P<0.01)$. The HA samples of different composting could be divided into three groups. The humification degree and electron transfer capacity of HA were different at each stage of diverse composting. The HA from mesophilic phase of composting were similar in most of the materials that clustered together, which had more aliphatic compounds and protein-like matter with an inhibition effect on the bioreduction of dissimilatory $\mathrm{Fe}(\mathrm{III})$. The HA from different lignocellulose-rich composts and the thermophilic phase of lignin-rich composts mainly clustered together except SW2, which had higher projection value on the arrow of $\mathrm{Fe}(\mathrm{II})$ formation, and $\mathrm{SUVA}_{290}$. The findings highlighted the role of HA from thermophilic phase of lignocellulose- and lignin-rich composting on stimulating the bioreduction of Fe(III) mainly based on the quinone moieties as well as other redox-active functional groups [3]. HA from the mature stage of composting, especially protein-rich materials, were grouped together but had shorter projection value on the $\mathrm{Fe}$ (II) formation. The shorter distance of these HA from the mature stage of composting to $\mathrm{C} 3,{ }^{13} \mathrm{C}-\mathrm{NMR} 3,{ }^{13} \mathrm{C}-\mathrm{NMR} 2$, and $\mathrm{SUVA}_{254}$ suggested that the high abundance of aromatic $\mathrm{C}$ structure with hydroxyl in humic-like substances would not obviously affect the electron transfer process of Fe(III) reduction by Shewanella oneidensis MR-1.

Taking the aforementioned information into account, our results suggested that the HA from lignocellulose- and lignin-rich composting, especially in the thermophilic phase promoted obviously the bioreduction of $\mathrm{Fe}(\mathrm{III})$, and HA from protein-rich materials suppressed significantly the $\mathrm{Fe}(\mathrm{II})$ production. Aromaticity of HA is not a reason for the electron transfer, while quinone/hydroquinone groups in HA are the major contributors to redox reaction between $\mathrm{Fe}(\mathrm{III}), \mathrm{HA}$ and microorganisms. The HA from diverse composts has different redox-active potential for Fe reduction, mainly because the origin and stages of composting affects the humification degree and chemical structures of HA, leading to different amount, structures and the redox activity of functional groups such as phenolic, alcoholic, quinone and ketone groups, nitrogen and sulfur redox-active moieties, as well as organic-metal chelates [8].

$\mathrm{Fe}(\mathrm{III})$ is an important terminal electron shuttles to stimulate the biodegradation of organic contaminants [26]. Dissimilatory iron reduction often occurs in soils, which caused the release of inorganic compounds that are bound to Fe(III) oxides and the soluble Fe(II) to be leached from the soil [27]. Considering the different stimulation capacity of HA from diverse composting, it can be reasonably concluded that the HA of composts will play an important role on heavy metal transformation and organic pollutant degradation in the contaminated soils. When composts are applied to soils, composts can be used in different ways based on the chemical structures and electron transfer capacity 
of HA. HA-rich composts from lignocellulose- and lignin-rich materials are more suitable bioresources for wide-ranging applications to catalyze the redox-mediated reactions of pollutants for contaminated soils remediation.

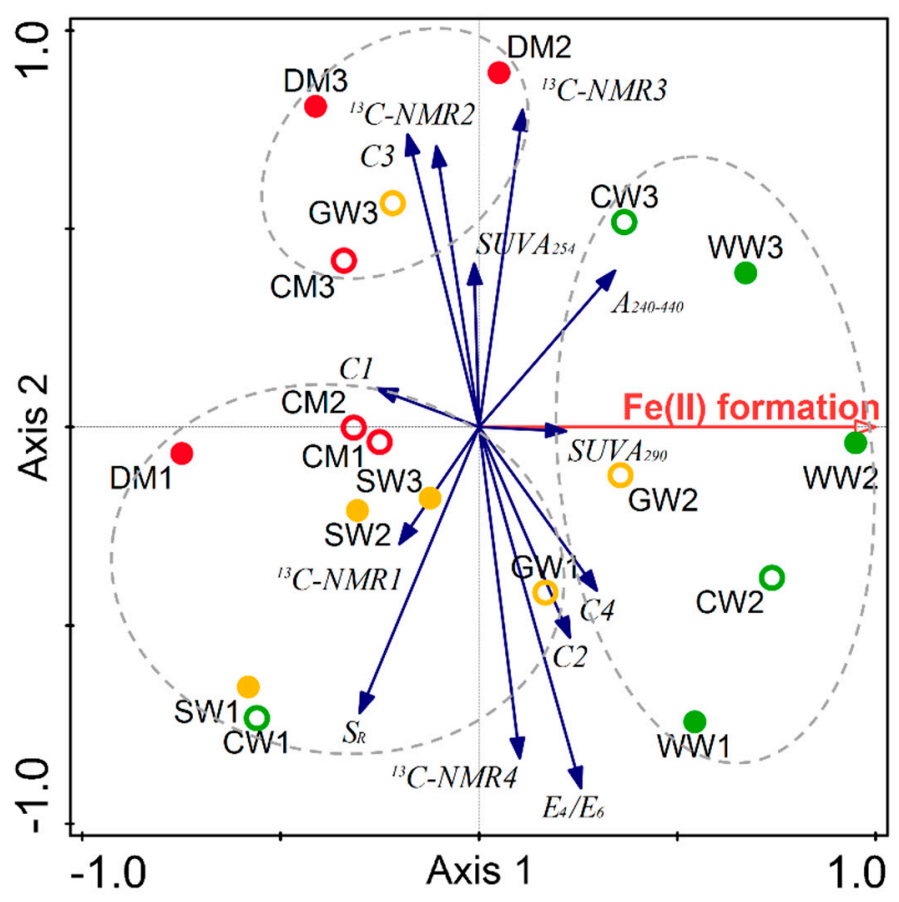

Figure 6. Redundancy analysis of the correlation between the redox-active functional groups of HA and $\mathrm{Fe}(\mathrm{III})$-citrate bioreduction for HA samples from different composting. The red, green and yellow circles represented the treatments with adding HA from protein-, lignocellulose- and lignin-rich composting, respectively. Acronyms definitions can be found in Materials and Methods.

\section{Materials and Methods}

\subsection{Preparation of Shewanella oneidensis $M R-1$}

Shewanella oneidensis MR-1 was grown aerobically from frozen $\left(-80^{\circ} \mathrm{C}\right)$ stock to lag-log phase in a Luria-Bertani (LB) broth at $30^{\circ} \mathrm{C}$. The cells were harvested by centrifugation at $3600 \mathrm{~g}$ for $10 \mathrm{~min}$ at $4{ }^{\circ} \mathrm{C}$ when it reached the exponential phase, washed twice with sterile $30 \mathrm{mM}$ of anoxic bicarbonate buffer $(\mathrm{pH}=7)$ and suspended before use in the following reduction studies. The concentrations of the strains were $1 \times 10^{7} \mathrm{CFU} \mathrm{mL}{ }^{-1}$. All growth media and containers used in this study were autoclaved $\left(121^{\circ} \mathrm{C}, 20 \mathrm{~min}\right)$ prior to incubation.

\subsection{Extraction and analysis of HA from Different Composting}

Humic acid (HA) samples were extracted from three main stages (i.e., mesophilic phase, thermophilic phase and mature phase) of different composting of six raw materials, including chicken manure (CM), dairy manure (DM), cabbage wastes (CW), weeds wastes (WW), straw wastes (SW) and green wastes (GW). Details of composting process and relevant properties have been described previously in Zhao et al. [17]. Each compost pile was more than 2 ton, and the piles were turned mechanically every 7 days at Shanghai Songjiang Composting plant, China. The extraction of HA followed the procedure of $\mathrm{Wu}$ et al. [9]. Compost samples $(10 \mathrm{~g})$ were mixed with $0.1 \mathrm{M}(\mathrm{NaOH}+$ $\mathrm{Na}_{4} \mathrm{P}_{2} \mathrm{O}_{7}$ ) at 1:10 (w: v) ratio for shaking $24 \mathrm{~h}$ with rotational speed $150 \mathrm{rpm}$. After centrifugation at $10,000 \mathrm{rpm}$ for $15 \mathrm{~min}$, the supernatant was filtered through a $0.45 \mu \mathrm{m}$ membrane and then acidified to $\mathrm{pH} 1$ with $6 \mathrm{M}$ hydrochloric acid $(\mathrm{HCl})$. HA was separated by centrifugation at 11,000 rpm for $15 \mathrm{~min}$ and suspended in a solution of $0.1 \mathrm{M} \mathrm{HCl} / 0.3 \mathrm{M}$ hydrogen fluoride to remove mineral impurities and 
dialyzed until the elimination of chloride ions. All chemicals were analytical reagent grade or higher and were purchased from Sinopharm Chemical Reagent Co., Ltd. (Shanghai, China).

UV-Vis spectroscopy, fluorescence spectroscopy, and ${ }^{13} \mathrm{C}-\mathrm{NMR}$ spectra were carried out to analyze the chemical structures of HA. Prior to fluorescence and UV-Vis analysis, total organic carbon (TOC) of all the samples was measured with an Analytik Jena model Multi N/C 2100 TOC analyzer (Jena, Germany) and the concentrations of HA were adjusted to $10 \mathrm{mg} \mathrm{L}^{-1}$.

UV-Vis spectroscopy was performed with a Shimadzu model UV-1700 PC spectrophotometer. Specific ultraviolet absorbance at $254 \mathrm{~nm}\left(\mathrm{SUVA}_{254}\right)$ and $290 \mathrm{~nm}\left(\mathrm{SUVA}_{290}\right)$ was calculated as the absorbance divided by the TOC concentration, and the absorbance ratio at 465 and $665 \mathrm{~nm}\left(\mathrm{E}_{4} / \mathrm{E}_{6}\right)$ was used to characterize the humification degree of HA. The integral area was calculated from 240 to $400 \mathrm{~nm}$, designated as $\mathrm{A}_{240-400}$, which was referred to the presence of the aromatic rings of polar functional groups [28]. The slope ratio or $S_{R}$, the ratio of the slope of the shorter ultraviolet absorbance wavelength region $(275-295 \mathrm{~nm})$ to that of the longer wavelength region $(350-400 \mathrm{~nm})$, was selected to determine the molecular weight [15].

Fluorescence spectroscopy was recorded using a Perkin-Elmer model LS50B fluorescence spectrophotometer in a clear quartz cuvette. Excitation-emission matrices (EEMs) spectra were recorded for excitation (200-450 nm) and emission $(280-550 \mathrm{~nm})$ wavelengths at intervals of $5 \mathrm{~nm}$ with a scan speed of $2400 \mathrm{~nm} \mathrm{~min}{ }^{-1}$. The EEMs were blank subtracted, corrected for inner-filter effects and instrument-specific biases, and normalized to the Raman area [29]. Parallel factor (PARAFAC) analysis of the EEMs spectral data was carried out in MATLAB 2013a (Mathworks, Natick, MA) with the DOMFluor toolbox (www.models.life.ku.dk) to identify the co-varied independently components. The concentration scores of the PARAFAC components were expressed as maximum fluorescence intensity (Fmax) (R.U.) for each modeled component [30].

Solid state ${ }^{13} \mathrm{C}-\mathrm{NMR}$ data of HA were acquired with a Bruker AV-300 spectrometer equipped with a direct polarization magic angle spinning (DP-MAS) probe, which were performed according to the method of Amir et al. [31]. The solutions for NMR were prepared by dissolving $100 \mathrm{mg}$ of the freeze-dried $\mathrm{HA}$ in $1 \mathrm{~mL}$ of $0.5 \mathrm{M} \mathrm{NaOD} / \mathrm{D}_{2} \mathrm{O}$. On the basis of qualitative analysis, the ${ }^{13} \mathrm{C}-\mathrm{NMR}$ spectra are subdivided into four main resonance regions (i.e., ${ }^{13} \mathrm{C}-\mathrm{NMR} 1,{ }^{13} \mathrm{C}-\mathrm{NMR} 2,{ }^{13} \mathrm{C}-\mathrm{NMR} 3$, and $\left.{ }^{13} \mathrm{C}-\mathrm{NMR} 4\right)$, which were 0-55 ppm (aliphatic carbon), 55-110 ppm (aliphatic carbon substituted with $\mathrm{O}$ or N), 110-165 ppm (aromatic carbon), and 165-200 ppm (carboxylic carbon) [32]. The proportion of each type of carbon was calculated by integrating the spectral regions.

\subsection{Batch Experiments of Dissimilatory Fe(III) Reduction}

Dissimilatory $\mathrm{Fe}(\mathrm{III})$ reduction assays were set up in triplicate in serum bottles containing $50 \mathrm{~mL}$ of basal medium with sodium lactate $(5 \mathrm{mM})$ as an electron donor, $20 \mathrm{mM} \mathrm{Fe}(\mathrm{III})$-citrate as an electron acceptor, Shewanella oneidensis MR-1 cells $\left(10^{7}\right.$ cells mL $\left.{ }^{-1}\right)$, and HA (final concentration of $100 \mathrm{mg} \mathrm{L}^{-1}$ ). Only sodium lactate and Fe(III)-citrate were added as a blank control (CK1). Controls (CK2) were prepared without HA addition. Various treatments were applied as shown in Table 2. The $\mathrm{pH}$ values were adjusted to $7.0-7.5$ with trace metal grade $1.0 \mathrm{M} \mathrm{NaOH}$ or $\mathrm{HCl}$. The reaction solution purged with $100 \% \mathrm{~N}_{2}$ for $30 \mathrm{~min}$ and static incubation in anoxic glovebox $\left(\mathrm{N}_{2}\right.$ atmosphere, at $\left.30^{\circ} \mathrm{C}, \mathrm{O}_{2}<0.1 \mathrm{ppm}\right)$. Samples were periodically extracted with $1 \mathrm{M} \mathrm{HCl}$ at 1:1 (v: v) ratio, then removed with sterile needles and syringes, and filtered through a $0.22 \mu \mathrm{m}$ membrane filter to analyze the total $\mathrm{Fe}(\mathrm{II})$ concentration with phenanthroline assay in an anaerobic chamber until Fe(II) became stable [33]. Absorbance was measured immediately with an ultraviolet-visible spectrophotometer (Shimadzu UV-1800, Tokyo, Japan) at $510 \mathrm{~nm}$. 
Table 2. Different treatments of batch experiments for dissimilatory Fe(III) reduction.

\begin{tabular}{cccccc}
\hline \multirow{2}{*}{ Treatment } & $\begin{array}{c}\text { Sodium } \\
\text { Lactate and } \\
\text { Fe(III)-citrate }\end{array}$ & $\begin{array}{c}\text { Shewanella } \\
\text { oneidensis } \\
\text { MR-1 }\end{array}$ & & \multicolumn{3}{c}{ Humic Acids } \\
\cline { 4 - 6 } & + & - & Mesophilic & Thermophilic & Mature \\
Phase & Phase & Phase \\
\hline $\mathrm{CK} 1$ & + & + & - & - & - \\
$\mathrm{CK} 2$ & + & + & - & - & - \\
$\mathrm{HA}(\mathrm{X} 1)$ & + & + & - & + & - \\
$\mathrm{HA}(\mathrm{X} 2)$ & + & + & - & - & + \\
$\mathrm{HA}(\mathrm{X} 3)$ & & + & & - & - \\
\hline
\end{tabular}

$\mathrm{X}$ represented the different materials composting, including chicken manure (CM), dairy manure (DM), cabbage wastes $(\mathrm{CW})$, weeds wastes (WW), straw wastes (SW) and green wastes (GW).

\subsection{Statistical Analyses}

Figure processing was generated by Origin 9.1 software (OriginLab, Los Angeles, USA). SPSS version 22.0 was used for the analysis of variance (ANOVA), and Pearson correlation analysis. The potential reduction of $\mathrm{Fe}(\mathrm{III})$-citrate was fitted to mathematical equations by the non-linear least-square curve fitting technique (Marquardt-Levenberg algorithm) using MATLAB v.19.0 software. $\mathrm{Fe}(\mathrm{III})_{\mathrm{t}}=\mathrm{Fe}(\mathrm{II})_{0}+\mathrm{Fe}(\mathrm{III})_{0}\left[1-\exp \left(-\mathrm{k}_{\text {red }} \mathrm{t}\right)\right]$, where $\mathrm{Fe}(\mathrm{II})_{\mathrm{t}}$ is the $\mathrm{Fe}(\mathrm{II})$ concentration at time $\mathrm{t}, \mathrm{Fe}(\mathrm{II})_{0}$ is the initial Fe (II) concentration, $\mathrm{Fe}(\mathrm{III})_{0}$ is the initial Fe(III) measured values. Redundancy analysis (RDA) was performed to analyze the multivariate relationships between the chemical structures of HA and $\mathrm{Fe}(\mathrm{III})$-citrate bioreduction by Canoco (Version 5.0, Centre for Biometry, Wageningen, The Netherlands). Monte Carlo reduced model tests with 499 unrestricted permutations were also used to evaluate the significance of the first canonical axis and of all canonical axes together. Statistical significance was kept at $P<0.05$ for all analyses.

\section{Conclusions}

This study provided comprehensive information on the chemical structures of HA from different stages of composting derived from protein-, lignocellulose- and lignin-rich materials. Quinone/hydroquinone groups in HA are the major contributors to redox reaction between Fe(III), HA, and microorganisms, but HA from diverse origins and stages of composting has different humification degree and different amount, structures, and the redox activity of functional groups, leading to different redox-active potential for catalyzing the bioreduction of Fe(III)-citrate by Shewanella oneidensis MR-1. The HA from lignocellulose- and lignin-rich composting, especially in the thermophilic phase promoted obviously the bioreduction of $\mathrm{Fe}(\mathrm{III})$, and HA from protein-rich materials suppressed significantly the $\mathrm{Fe}(\mathrm{II})$ production.

Author Contributions: Y.W. and B.X. conceived and designed the experiments; Y.W., W.T. and X.L. performed the experiments; Y.W., and X.L. analyzed the data with suggestions by F.Z., W.T. and Z.W.; Y.W. and W.T. wrote the paper; Z.W., F.Z. and B.X. proofed the paper.

Funding: This work was funded by the China Postdoctoral Science Foundation (No. 2017M620801), and National Natural Science Foundation of China (No. 51808519).

Acknowledgments: We thank the editor and two anonymous reviewers for their insightful comments that greatly improved this manuscript.

Conflicts of Interest: The authors declare that they have no conflict of interest.

\section{Abbreviations}

CM1; CM2; CM3: Chicken manure composting at the mesophilic phase; Chicken manure composting at the thermophilic phase; Chicken manure composting at the maturation phase, respectively. DM1; DM2; DM3: Dairy manure composting at the mesophilic phase; Dairy manure composting at the thermophilic phase; Dairy manure composting at the maturation phase, respectively. CW1; CW2; CW3: Cabbage wastes composting at the mesophilic phase; Cabbage wastes composting at the thermophilic phase; Cabbage wastes composting at the maturation phase, respectively. WW1; WW2; WW3: Weeds wastes composting at the mesophilic phase; Weeds wastes 
composting at the thermophilic phase; Weeds wastes composting at the maturation phase, respectively. SW1; SW2; SW3: Straw wastes composting at the mesophilic phase; Straw wastes composting at the thermophilic phase; Straw wastes composting at the maturation phase, respectively. GW1; GW2; GW3: Green wastes composting at the mesophilic phase; Green wastes composting at the thermophilic phase; Green wastes composting at the maturation phase, respectively. HA: Humic acids. ${ }^{13} \mathrm{C}$ NMR: Carbon 13 nuclear magnetic resonance.

\section{References}

1. Liu, G.; Qiu, S.; Liu, B.; Pu, Y.; Gao, Z.; Wang, J.; Jin, R.; Zhou, J. Microbial reduction of Fe (III)-bearing clay minerals in the presence of humic acids. Sci. Rep. 2017, 7, 45354. [CrossRef] [PubMed]

2. Zhao, X.; Tan, W.; Dang, Q.; Li, R.; Xi, B. Enhanced biotic contributions to the dechlorination of pentachlorophenol by humus respiration from different compostable environments. Chem. Eng. J. 2019, 361, 1565-1575. [CrossRef]

3. Klüpfel, L.; Piepenbrock, A.; Kappler, A.; Sander, M. Humic substances as fully regenerable electron acceptors in recurrently anoxic environments. Nat. Geosci. 2014, 7, 195. [CrossRef]

4. Stern, N.; Mejia, J.; He, S.; Yang, Y.; Ginder-Vogel, M.; Roden, E.E. Dual role of humic substances as electron donor and shuttle for dissimilatory iron reduction. Environ. Sci. Technol. 2018, 52, 5691-5699. [CrossRef]

5. Wei, Y.; Zhao, Y.; Shi, M.; Cao, Z.; Lu, Q.; Yang, T.; Fan, Y.; Wei, Z. Effect of organic acids production and bacterial community on the possible mechanism of phosphorus solubilization during composting with enriched phosphate-solubilizing bacteria inoculation. Bioresour. Technol. 2018, 247, 190-199. [CrossRef] [PubMed]

6. Wang, C.; Tu, Q.; Dong, D.; Strong, P.; Wang, H.; Sun, B.; Wu, W. Spectroscopic evidence for biochar amendment promoting humic acid synthesis and intensifying humification during composting. J. Hazard. Mater. 2014, 280, 409-416. [CrossRef]

7. Gao, X.; Tan, W.; Zhao, Y.; Wu, J.; Sun, Q.; Qi, H.; Xie, X.; Wei, Z. Diversity in the Mechanisms of Humin Formation during Composting with Different Materials. Environ. Sci. Technol. 2019, 53, 3653-3662. [CrossRef]

8. Lipczynska-Kochany, E. Humic substances, their microbial interactions and effects on biological transformations of organic pollutants in water and soil: A review. Chemosphere 2018, 202, 420-437. [CrossRef] [PubMed]

9. Wu, J.; Zhao, Y.; Zhao, W.; Yang, T.; Zhang, X.; Xie, X.; Cui, H.; Wei, Z. Effect of precursors combined with bacteria communities on the formation of humic substances during different materials composting. Bioresour. Technol. 2017, 226, 191-199. [CrossRef]

10. Lovley, D.R.; Coates, J.D.; Blunt-Harris, E.L.; Phillips, E.J.; Woodward, J.C. Humic substances as electron acceptors for microbial respiration. Nature 1996, 382, 445-448. [CrossRef]

11. Wu, J.; Zhao, Y.; Yu, H.; Wei, D.; Yang, T.; Wei, Z.; Lu, Q.; Zhang, X. Effects of aeration rates on the structural changes in humic substance during co-composting of digestates and chicken manure. Sci. Total Environ. 2019, 658, 510-520. [CrossRef] [PubMed]

12. Xi, B.; Zhao, X.; He, X.; Huang, C.; Tan, W.; Gao, R.; Zhang, H.; Li, D. Successions and diversity of humic-reducing microorganisms and their association with physical-chemical parameters during composting. Bioresour. Technol. 2016, 219, 204-211. [CrossRef] [PubMed]

13. Nakasaki, K.; Le, T.H.T.; Idemoto, Y.; Abe, M.; Rollon, A.P. Comparison of organic matter degradation and microbial community during thermophilic composting of two different types of anaerobic sludge. Bioresour. Technol. 2009, 100, 676-682. [CrossRef] [PubMed]

14. Kulkarni, H.V.; Mladenov, N.; McKnight, D.M.; Zheng, Y.; Kirk, M.F.; Nemergut, D.R. Dissolved fulvic acids from a high arsenic aquifer shuttle electrons to enhance microbial iron reduction. Sci. Total Environ. 2018, 615, 1390-1395. [CrossRef]

15. Helms, J.R.; Stubbins, A.; Ritchie, J.D.; Minor, E.C.; Kieber, D.J.; Mopper, K. Absorption spectral slopes and slope ratios as indicators of molecular weight, source, and photobleaching of chromophoric dissolved organic matter. Limnol. Oceanogr. 2008, 53, 955-969. [CrossRef]

16. Yuan, Y.; He, X.; Xi, B.; Li, D.; Gao, R.; Tan, W.; Zhang, H.; Yang, C.; Zhao, X. Polarity and molecular weight of compost-derived humic acid affect Fe(III) oxides reduction. Chemosphere 2018, 208, 77-83. [CrossRef]

17. Zhao, X.; He, X.; Xi, B.; Gao, R.; Tan, W.; Zhang, H.; Huang, C.; Li, D.; Li, M. Response of humic-reducing microorganisms to the redox properties of humic substance during composting. Waste Manag. 2017, 70, 37-44. [CrossRef] 
18. Tan, W.; Xi, B.; Wang, G.; Jiang, J.; He, X.; Mao, X.; Gao, R.; Huang, C.; Zhang, H.; Li, D. Increased electron-accepting and decreased electron-donating capacities of soil humic substances in response to increasing temperature. Environ. Sci. Technol. 2017, 51, 3176-3186. [CrossRef]

19. Ratasuk, N.; Nanny, M.A. Characterization and Quantification of Reversible Redox Sites in Humic Substances. Environ. Sci. Technol. 2007, 41, 7844-7850. [CrossRef]

20. Stedmon, C.A.; Bro, R. Characterizing dissolved organic matter fluorescence with parallel factor analysis: A tutorial. Limnol. Oceanogr. Meth. 2008, 6, 572-579. [CrossRef]

21. Chen, W.; Westerhoff, P.; Leenheer, J.A.; Booksh, K. Fluorescence Excitation-Emission Matrix Regional Integration to Quantify Spectra for Dissolved Organic Matter. Environ. Sci. Technol. 2003, 37, 5701-5710. [CrossRef] [PubMed]

22. Pérez, M.G.; Martin-Neto, L.; Saab, S.C.; Novotny, E.H.; Milori, D.M.; Bagnato, V.S.; Colnago, L.A.; Melo, W.J.; Knicker, H. Characterization of humic acids from a Brazilian Oxisol under different tillage systems by EPR, ${ }^{13}$ C NMR, FTIR and fluorescence spectroscopy. Geoderma 2004, 118, 181-190. [CrossRef]

23. Tan, K.H. Humic Matter in Soil and the Environment: Principles and Controversies; CRC Press: Boca Raton, FL, USA, 2014.

24. Zhou, Y.; Selvam, A.; Wong, J.W.C. Evaluation of humic substances during cocomposting of food waste, sawdust and Chinese medicinal herbal residues. Bioresour. Technol. 2014, 168, 229-234. [CrossRef] [PubMed]

25. Smilek, J.; Sedlác`ek, P.; Kalina, M.; Klucáková, M. On the role of humic acids' carboxyl groups in the binding of charged organic compounds. Chemosphere 2015, 138, 503-510. [CrossRef]

26. Lovley, D.R.; Holmes, D.E.; Nevin, K.P. Dissimilatory Fe(III) and Mn(IV) reduction. Adv. Microb. Physiol. 2004, 49, 219-286. [PubMed]

27. Xu, Y.; He, Y.; Feng, X.; Liang, L.; Xu, J.; Brookes, P.C.; Wu, J. Enhanced abiotic and biotic contributions to dechlorination of pentachlorophenol during Fe(III) reduction by an iron-reducing bacterium Clostridium beijerinckii Z. Sci. Total Environ. 2014, 473-474, 215-223. [CrossRef]

28. Zhao, X.; Wei, Y.; Fan, Y.; Zhang, F.; Tan, W.; He, X.; Xi, B. Roles of bacterial community in the transformation of dissolved organic matter for the stability and safety of material during sludge composting. Bioresour. Technol. 2018, 267, 378-385. [CrossRef] [PubMed]

29. Cui, H.Y.; Zhao, Y.; Chen, Y.N.; Zhang, X.; Wang, X.Q.; Lu, Q.; Jia, L.M.; Wei, Z.M. Assessment of phytotoxicity grade during composting based on EEM/PARAFAC combined with projection pursuit regression. J. Hazard. Mater. 2017, 326, 10-17. [CrossRef] [PubMed]

30. Wei, Z.; Zhao, X.; Zhu, C.; Xi, B.; Zhao, Y.; Yu, X. Assessment of humification degree of dissolved organic matter from different composts using fluorescence spectroscopy technology. Chemosphere 2014, 95, 261-267. [CrossRef] [PubMed]

31. Amir, S.; Jouraiphy, A.; Meddich, A.; El Gharous, M.; Winterton, P.; Hafidi, M. Structural study of humic acids during composting of activated sludge-green waste: Elemental analysis, FTIR and ${ }^{13} \mathrm{C}$ NMR. J. Hazard. Mater. 2010, 177, 524-529. [CrossRef]

32. Trubetskoj, O.A.; Hatcher, P.G.; Trubetskaya, O.E. ${ }^{1}$ H-NMR and ${ }^{13}$ C-NMR spectroscopy of chernozem soil humic acid fractionated by combined size-exclusion chromatography and electrophoresis. Chem. Ecol. 2010, 26, 315-325. [CrossRef]

33. Tan, W.; Li, R.; Yu, H.; Zhao, X.; Dang, Q.; Jiang, J.; Wang, L.; Xi, B. Prominent Conductor Mechanism-Induced Electron Transfer of Biochar Produced by Pyrolysis of Nickel-Enriched Biomass. Catalysts 2018, 8, 573. [CrossRef]

(C) 2019 by the authors. Licensee MDPI, Basel, Switzerland. This article is an open access article distributed under the terms and conditions of the Creative Commons Attribution (CC BY) license (http://creativecommons.org/licenses/by/4.0/). 